(C) 2002 The Chemical Society of Japan

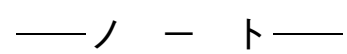

\title{
コーヒー殼による水中の銅 (II)および カドミウム(II)の捕集除去
}

\author{
(2001年 10 月 15 日受理)
}

南澤麿優覽*. 中嶋すぎ子・満江友紀・宮澤和 江・上野慶子・ 羽鳥 愛・宮島 讶子・星野真希枝・吉田章一郎 $・$ 高井信 治 ${ }^{\dagger}$

\section{1 緒言}

近年，環境・生体・高純度物質・機能性材料などに含まれる微 量金属イオンの簡易迅速濃縮分離法の研究が行われている.

特に溶媒抽出, 共沈分離法, イオン交換分離法, シリカゲルや ポリマーなどで表面修飾した捕集剤を用いた固相吸着分離法等の 活用・研究が盛んに行われている122)。しかし，いずれの方法も はん杂隹な操作や迅速性に問題点を残しているのが現状である ${ }^{3)}$.

一方，新世紀を迎えて，現在産業界は Green Chemistry の取 り組みが大前提となりつつある。著者らは, 資源の有効利用とい う観点から，金属捕集材として生物質材料の活用に着目した.

生物は, 生命維持の必須元素を能動的に取り込み, 特定の元素 を体内で濃縮・蓄積することがよく知られている，これらの性質 を利用して，木村 ${ }^{45)}$ は，活性炭やくるみ・落花生・羊毛などの 農業副産物を用い， $\operatorname{Orhan}^{6)}$ は，各種木の実の殼を用いて，水中 の重金属類の捕集除去を行っている．また，豊富なバイオマス資 源として幅広く活用されているキチンおよび誘導されたキトサン の応用も多く研究されている7)-9) . いずれの材料も, 素材そのま まの状態で用いるのは困難であり，化学処理等の二次処理が必要 となるなどの問題点が挙げられる.

本報では，生豆から焙煎・抽出過程を経て得られるコーヒ一殸 を使用した．生物質材料としてのコーヒ一殼の活用は十分になさ

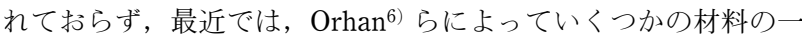
つとして報告されているのみである.

そこで，著者らは本報で初めて，吸着材としてのコーヒ一豆の 焙煎条件や産地の違いによる詳細な検討を行い，簡便な水中の重 金属の捕集除去に関して有用な知見を得た。

東京医薬専門学校生命工学技術科，134-8530 東京都江 戸川区東葛西 6-5-12

†東京大学生産技術研究所, 153-8505 東京都目黒区駒場 4-6-1

${ }^{\dagger}$ 東京電機大学理工学部, 350-0394 埼玉県比企郡鳩山町

\section{2 実験}

\section{1 コーヒー殼の調製}

コーヒー豆は, ライト, ミディアム, シティ, フルシティ, フ レンチの 5 段階に焙煎された，アラビカ種のブラジル，グァテ マラ，コロンビア，ロブスタ種のインドネシアの 4 種類を用い た. 各焙煎豆 $25 \mathrm{~g}$ を Philips 製コーヒーミルで 12 秒間粉砕し, Philips 製コーヒーメーカーを用いて, 蒸留水 $300 \mathrm{~mL}$ で抽出し た. 残分の豆殼を, さらに蒸留水中 $(300 \mathrm{~mL})$ 室温にてスター ラーで 1 時間攪拌し, 洗浄を行った.コーヒ一殼は洗浄ごとに 洗液を HPLC 測定した結果, 3 回の洗浄で殼からの有機物の溶 出が認められなくなったため, 洗浄回数を 3 回と決定した. 水 洗後, 温風乾燥機 $\left(105{ }^{\circ} \mathrm{C}\right)$ 中で一昼夜乾燥後デシケーター中で室 温まで放冷させて用いた。コーヒー殼の重量は，乾燥後 $50 \%$ ま で減少した.

なお、コーヒ一殼の洗浄・乾燥処理が重金属の吸着に及ぼす影 響を検討するため, 抽出後, 水洗・乾燥殼 $(\mathrm{A})$, 乾燥殼 $(\mathrm{B})$, 水洗殼 (C), 抽出のみの未処理殼(D)の 4 種類の処理を行ったインドネシ アロブスタ(ライト)殼を用意し，銅 (II)イオン含有試料水での吸

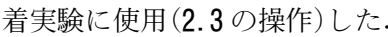

\section{2 試薬および装置}

銅 (II ) $(\mathrm{Cu}(\mathrm{II}))$ 標準液 (関東化学・原子吸光分析用) または力 ドミウム $($ II $)(\mathrm{Cd}$ (II)) 標準液 (関東化学・原子吸光分析用)を蒸 留水で希釈 $\left(5 \mathrm{mg} \mathrm{L}^{-1}\right)$ し, アンモニア水溶液 (和光純薬)で $\mathrm{pH}$ を 6.5-6.7 に調整したものを，試料水として用いた

重金属イオン濃度の測定は，セイコー電子工業製 SAS 7500 型 原子吸光分光光度計を使用した.

活性炭は，粉末の活性炭素(和光特級，和光純薬)を用いた。

\section{3 コーヒー殼への吸着実験操作}

コーヒー殼(A) と(B)は $2.5 \mathrm{~g}$, 乾燥していない(C) と(D)は $5.0 \mathrm{~g}$ を，2.2 で調製した試料水 $500 \mathrm{~mL}$ に加え，スターラーで攪拌し ながら放置した．分散液を 10 分ごとにシリンジで $25 \mathrm{~mL}$ サンプ リングし, メンブランフィルターで沪過後, 溶液の $\mathrm{pH}$ を測定 し，汇液中の金属イオン濃度を原子吸光分光光度計を用いて測定 した. 


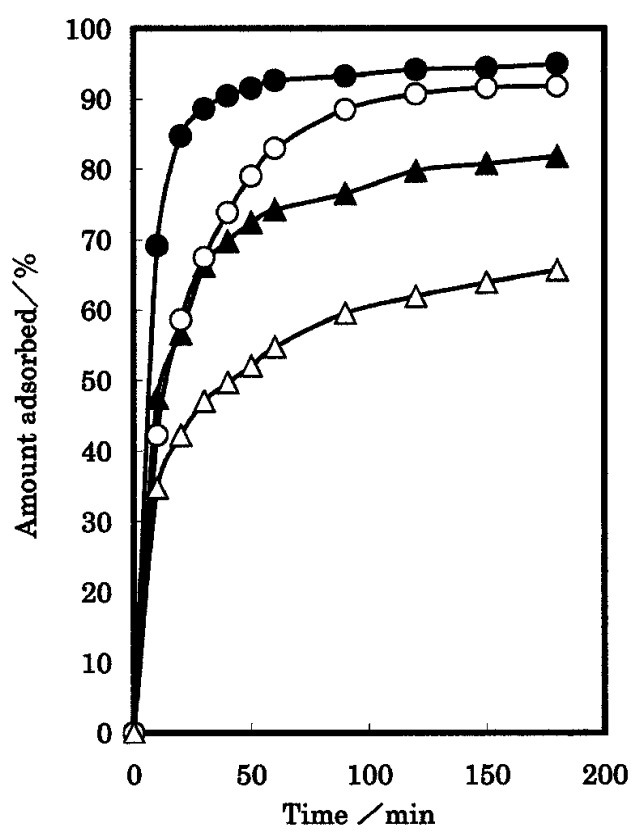

Fig. 1 Adsorption of $\mathrm{Cu}(\mathrm{II})$ ion on indonesia robusta coffee.

O: Washed and dried coffee (A), $\boldsymbol{\Delta}$ : dried coffee (B), $\bigcirc$ : washed coffee (C), $\triangle$ : untreated coffee (D).

\section{3 結果と考察}

\section{1 コーヒ一殼の調製条件の検討}

Fig. 1 に, 4 種の処理条件下で調製したインドネシアロブスタ （ライト)殼への $\mathrm{Cu}(\mathrm{II})$ イオンの吸着結果を示す。なお, 吸着率 は, 次式より求めた。

$$
\begin{aligned}
& \text { 吸着率 }(\%)=\frac{\left(C_{0}-C\right) \times 100}{C} \\
& C_{0} \text { : 試料水中重金属の初期濃度 } \\
& C: \text { 各測定時間ごとの重金属残存濃度 }
\end{aligned}
$$

Fig. 1 より, 試料水中の $\mathrm{Cu}(\mathrm{II})$ イオンは, 洗浄・乾燥した コーヒ一殼(A)を用いた場合, 吸着開始 10 分後には $70 \%$ 近く吸着 され, 約 60 分後にはほぼ平衡に達している.

180 分後のコーヒー殼への吸着量は $\mathrm{A}(94.5 \%)>\mathrm{C}(91.8 \%)>$ $\mathrm{B}(81.8 \%)>\mathrm{D}(65.7 \%)$ の順で減少し, 吸着の速さもほぼ同様な 傾向を示した.これより, コーヒ一殸の調製には水による洗浄や 乾燥が非常に有効な因子であることが示唆された.

洗浄と乾燥操作による吸着容量の増大は, コーヒ一殼から洗浄 によって有機物が溶出していることから，殼に残存している有機 物が吸着サイトの活性を阻害していることが推察され, さらに乾 燥によって細孔の数や細孔径が変化して表面積が大きくなったた め, 吸着率が増加したのではないかと推察される.

以上の結果より, 本実験では抽出後のコーヒ一殼は, 水洗·乾 燥後用いることとした.

\section{$3.2 \mathrm{Cu}(\mathrm{II})$ イオンの吸着に対するコーヒ一焙煎条件の影響}

5 段階に焙煎された, アラビカ種のブラジル, コロンビア, グ アテマラ，ロブスタ種のインドネシアの 4 種のコーヒー豆を用 い, 抽出 · 水洗 · 乾燥処理したコーヒ一殼への $\mathrm{Cu}(\mathrm{II})$ の吸着率
Table 1 Batch capacities of $\mathrm{Cu}(\mathrm{II})$ ion for the various roasted coffees

\begin{tabular}{cccccc}
\hline \multicolumn{7}{c}{ Amount adsorbed $/ \%^{\mathrm{a})}$} \\
\hline Coffee & Light & Medium & City & Fullcity & French \\
\hline Brazil & 92.3 & 94.7 & 95.5 & 94.9 & 91.4 \\
Columbia & 95.1 & 93.0 & 95.3 & 93.5 & 92.4 \\
Guatemala & 93.3 & 91.6 & 95.4 & 94.5 & 95.2 \\
Indonesia & 92.2 & 92.2 & 93.0 & 91.0 & 92.6
\end{tabular}

a) At $180 \mathrm{~min}$ after adsorption experiments.

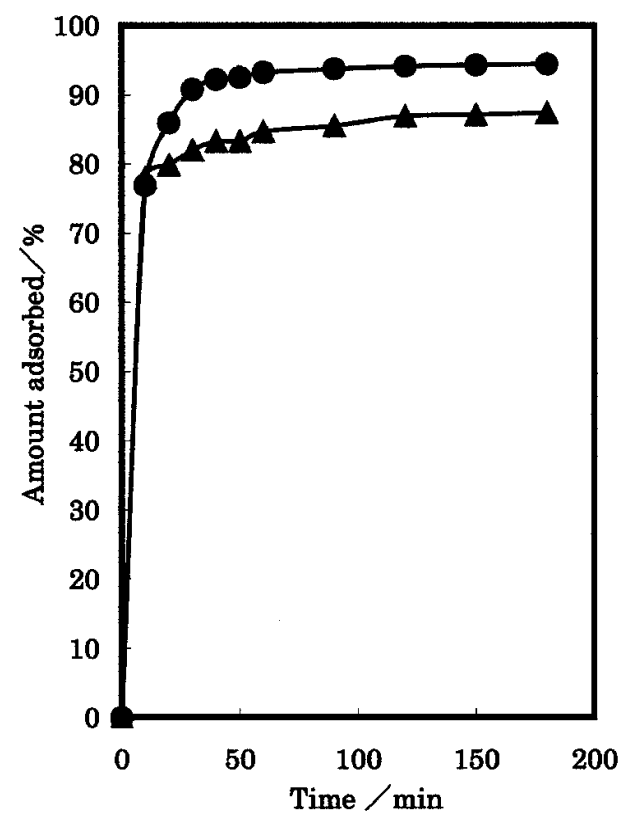

Fig. 2 Adsorptions of $\mathrm{Cd}($ II) ion on coffee and activated carbon.

: Blend coffee, $\boldsymbol{\Delta}$ : activated carbon.

を求めた結果を Table 1 に示す.

アラビカ種・ロブスタ種共に，すべての焙煎条件下でコーヒー 殼への $\mathrm{Cu}(\mathrm{II})$ イオンの吸着率は $91 \%$ 以上を示し, 焙煎抢よび コーヒーの種類による顕著な違いは認められなかった．試料水中 の $\mathrm{Cu}($ II $)$ イオンは，コーヒー殼を加えてから 10 分後にはすべ てのばい煎殼で $70 \%$ 以上が吸着し, 約 40 分後にはほぼ平衡に達 した。

これより, $\mathrm{Cu}(\mathrm{II})$ イオンを含む污染水からの重金属の除去に は，どのような焙煎状態のコーヒー殼でも活用でき，迅速性・簡 便性を有するかなり効果的な資材となると期待される.

\section{3 活性炭とコーヒ一殼との比較}

水洗・乾燥処理したコーヒ一殼と活性炭を用いた, $\mathrm{Cd}($ II) イ オンの吸着率の比較を試みた結果を Fig. 2, Table 2 に示す.

コーヒー殼は, 本報で用いた全種類・全焙煎状態のコーヒー 殸，およびこれらをすべて等量ずつブレンドしたものを調製し， 活性炭も等量用いて行った. Fig. 2 に示すように, コーヒー殼で は平衡に達する時間は活性炭とほぼ同等であり, しかも平衡時の 吸着率は活性炭より 10\%ほど高い結果を得た。 
Table 2 Batch capacities of $\mathrm{Cd}(\mathrm{II})$ ion for the various roasted coffees and activated carbon

\begin{tabular}{cccccc}
\hline \multicolumn{5}{c}{ Amount adsorbed $/ \%$ a) } \\
\hline $\begin{array}{c}\text { Blend Coffee } \\
\text { Activated carbon }\end{array}$ & \multicolumn{5}{c}{94.5} \\
\hline Coffee & Light & Medium & City & Fullcity & French \\
\hline Brazil & 95.3 & 95.7 & 96.8 & 97.0 & 95.9 \\
Columbia & 95.0 & 94.8 & 95.2 & 95.2 & 96.8 \\
Guatemala & 93.6 & 95.5 & 94.3 & 95.3 & 96.1 \\
Indonesia & 95.6 & 96.2 & 97.1 & 96.8 & 97.0 \\
\hline
\end{tabular}

a) At 180 min after adsorption experiments.

Table 2 より，コーヒー殼への吸着率はいずれの場合も $94-$ 97\%を示し, 活性炭(87.5\%)よりも優れた吸着率を示した.

著者らの結果は $\mathrm{Cd}(\mathrm{II})$ イオンに関してだけではあるが，コー ヒ一殼は活性炭よりも極めて良好な捕集除去作用を示した．活性 炭は Black magic と呼ばれ，工業的な用途から家庭の中まで非 常に広範囲に利用されている11．水溶液中の重金属の捕集除去剤 としても注目され，多くの報告がなされている．しかしコーヒー
殼では，水洗・乾燥という非常に簡便な処理法のみで $\mathrm{Cu}(\mathrm{II})$, $\mathrm{Cd}$ (II) イオンの高い吸着量が得られたことは大変興味深く, コーヒ一殼の金属捕集能力の高さがうかがわれる.

またコーヒ一殼は廃棄物としての絶対量が多く, 市販品の多く がブレンドされた状態で商品化されている現状をふまえると，焙 煎状態やコーヒーの種類に影響を受けなかったことは有利であ り，今後，価格面も含め環境保全に寄与できる資源として大いに 期待される。

1）大関邦夫，糠塚いそし，ぶんせき，4，44(1992).

2）奥谷忠雄，鵜沢 惊，分化，44,663(1995).

3）寺田喜久雄，ぶんせき，7, 56(1993)。

4）木村 優, 公害と対策, 19, 341(1983).

5）木村 優, 山下博美, 駒田順子, 分化, 35, 400 (1986).

6) Y. Orhan, H. Buyukgungor, Wat. Sci. Tech., 28, 247 (1993).

7) W. S. Wan Ngah, I. M. Isa, J. Appl. Polym. Sci., 67, 1067 (1998)

8) H. Minamisawa, H. Iwanami, N. Arai, T. Okutani, Anal. Chim. Acta, 378, 279(1999).

9) H. Minamisawa, N. Arai, T. Okutani, Anal. Sci., 15, 269 (1999).

\title{
Removal of Copper (II) and Cadmium (II) in Water by Use of Roasted Coffee Beans
}

Mayumi Minamisawa*, Sugiko Nakajima, Yuki Mitsue, Kazue Miyazawa, Keiko Ueno, Ai Hatori, Saeko Miyajima, Makie Hoshino, Shoichiro YoshidA ${ }^{\dagger}$ and Nobuharu TAKaI ${ }^{\dagger \dagger}$

\author{
Tokyo College of Medico-Pharmaco Technology; 6-5-12 Higashikasai, Edogawa-ku, \\ Tokyo 134-8530 Japan \\ ${ }^{\dagger}$ Institute of Industrial Science, The University of Tokyo; 4-6-1 Komaba, Meguro-ku, \\ Tokyo 153-8505 Japan \\ ${ }^{\dagger+}$ Department of Biotechnology, College of Science and Engineering, Tokyo Denki \\ University; Hatoyama, Hiki-gun, Saitama 350-0394 Japan
}

Adsorption behavior of heavy metals on arabica and robusta roasted coffee beans treated in 5 roasting degrees was investigated. The coffee beans residue after extraction with hot water were suspended in aqueous solutions $(\mathrm{pH}=c a .6 .6)$ containg $\mathrm{Cu}($ II $)$ or $\mathrm{Cd}(\mathrm{II})$ and the amount of heavy metal remaining in the solution was determined on an atomic absorption spectrophotometer. Adsorption ratios of $\mathrm{Cu}(\mathrm{II})$ were 60.5 and $79.6 \%$ for the light and French roasted coffee beans of Indonesia robusta employed as adsorbent, respectively. However, when the roasted coffee beans were washed with distilled water and then air-dried prior adsorption experiments, the adsorption ratios of $\mathrm{Cu}$ were 92.2 and $92.6 \%$, respectively and that of $\mathrm{Cd}$ was 95.6 and $97.0 \%$. Thus, the heavy metals were almost removed from aqueous solution by use of the roasted coffee beans with washing and drying treatments. 